\title{
Deletion analysis of tumor and urinary DNA to detect bladder cancer: Urine supernatant versus urine sediment
}

\author{
TIBOR SZARVAS ${ }^{1}$, ILONA KOVALSZKY ${ }^{1}$, KATALIN BEDI $^{1}$, ATTILA SZENDROI ${ }^{2}$, ATTILA MAJOROS $^{2}$, \\ PÉTER RIESZ ${ }^{2}$, TIBOR FÜLE ${ }^{1}$, VIKTÓRIA LÁSZLÓ ${ }^{1}$, ANDRÁS KISS ${ }^{3}$ and IMRE ROMICS ${ }^{2}$ \\ ${ }^{1}$ First Department of Pathology and Experimental Cancer Research, Semmelweis University, H-1085 Budapest; \\ ${ }^{2}$ Department of Urology, Semmelweis University, H-1091 Budapest; ${ }^{3}$ Second Department \\ of Pathology, Semmelweis University, H-1082 Budapest, Hungary
}

Received January 10, 2007; Accepted March 30, 2007

\begin{abstract}
The accumulation of genetic alterations plays a role in the evolution of bladder cancer. These changes can be detected in the urine by DNA analysis of the cells exfoliated from the bladder wall enabling us to detect bladder cancer. The urine supernatant, besides the urine sediment, contains DNA, however in a much smaller amount. The origin of DNA in these two fractions is probably different. Our aim was to evaluate which fraction (supernatant or sediment) provides more reliable results in detecting tumors. We analyzed blood, urine and tumor samples taken from 80 individuals (44 patients with bladder cancer, 20 control patients and 16 healthy volunteers) by using 12 microsatellite markers mapped on 6 chromosomes. Microsatellite alterations were detected in the urine sediment and supernatant in $86 \%$ of the cancer cases. Urine sediment alone had a sensitivity of $68 \%$, while urine supernatant alone indicated aberrations in $80 \%$ of the tumors. In the superficial (Ta/T1) cases, a considerable difference in sensitivity, 84 vs. $67 \%$, was found between the two fractions in favor of urine supernatant. We also detected deletions in the control groups, although in a much lower proportion. Loss of the 16q24 chromosomal region showed a significant correlation with tumor stage $(\mathrm{p}=0.02)$. Microsatellite analysis of the urine is an efficient and noninvasive molecular method to detect bladder cancer. The analysis of free DNA in the urine supernatant provides a higher detection rate. The marker on the chromosomal region $16 q 24$ is suggested to have a prognostic value.
\end{abstract}

Correspondence to: Dr Tibor Szarvas, First Department of Pathology, Semmelweis University, H-1085 Budapest, Ülloi út 26, Hungary

E-mail: sztibusz@t-online.hu sztibusz@gmail.com

Key words: bladder cancer, microsatellite, loss of heterozygosity, deletion, fragment analysis, urine

\section{Introduction}

Multiple genetic changes are involved in the evolution and progression of human cancer $(1,2)$. Besides oncogene activation, the inactivation of tumor suppressor genes is a key feature of tumorigenesis. Tumor suppressor genes may become inactive owing to several different mechanisms. The first hit is often deletion or recombination of a tumor suppressor gene, whereas the second hit can be hypermethylation of the promoter, point mutation or another deletion.

Microsatellites are short, polymorphic, tandem repeat segments dispersed throughout the human genome. Microsatellite markers are considered to be effective in detecting genetic alterations, such as microsatellite instability (MSI) and loss of heterozygosity $(\mathrm{LOH})$ in human cancer $(3,4)$.

Bladder cancer is the fourth most common malignant neoplasm in men and the eighth in women (5). The two main risks of these tumors are their high recurrence rate and progression depending on the initial tumor stage and grade (6). This emphasizes the importance of their early detection and a strict follow-up. Cystoscopy, as the 'gold standard' method, is invasive and uncomfortable. Urine cytology is a complementary diagnostic procedure. It does not provide, however, a reliable result in the case of papillary tumors since its sensitivity depends on the tumor grade $(50 \%)(7,8)$.

Frequent $\mathrm{LOH}$ has been reported in bladder carcinoma on chromosomes $3,4,5,8,9,11,13,17$ and 18 involving the p53 and p16 tumor suppressor genes (9-13). Further studies demonstrated that mutated cancerous DNA is also detected in the corresponding urine sample $(11,14)$. However, the presence of normal DNA derived from non-cancerous cells might interfere with the analysis. The ratio between the normal and cancerous epithelial cells in the urine sediment is probably related to tumor size. Therefore, analysis of the urine sediment provides a less sensitive result in noninvasive cases. On the other hand, the free DNA level in body fluids is elevated in cancer patients. The urine supernatant is suggested to contain free DNA that mainly originates from the tumor (15-19). This offers the possibility to enhance the sensitivity of microsatellite analysis by examining the free DNA isolated from the urine supernatant. 


\section{Materials and methods}

Patients. Matched blood, urine and tumor samples were collected from 44 patients (13 female, 31 male, and average age of 74 years) who underwent surgical resection of bladder cancer at the Department of Urology. The diagnosis was confirmed and tumors were graded after surgical resection by histological examination. The stages/grades were Ta in 7 cases, $\mathrm{T} 1$ in $18, \mathrm{~T} 2$ in 18 , and $\mathrm{T} 3$ in one case. Tumor samples in 18 cases and urine sediment samples in 4 cases were not available for molecular analysis. Blood and urine samples were also collected from 20 control patients with nonmalignant urinary diseases and 16 healthy individuals without any previous serious urological anamnesis. This study was approved by the Ethics Committee of the Semmelweis University.

Sample treatment. Tumor specimens obtained during surgery were immediately frozen. Blood and urine samples had been collected on the previous day. The urine was centrifuged at $3000 \mathrm{x} \mathrm{g}$ at $4^{\circ} \mathrm{C}$ for $5 \mathrm{~min}$. The supernatant was separated, and the sediment was suspended in $0.5 \mathrm{ml} 1 \mathrm{X}$ PBS. Samples were stored at $-70^{\circ} \mathrm{C}$ before further processing.

DNA extraction. DNA was extracted from blood, tumor and the separated urine samples (described above) using Roche High Pure Template Isolation kit (Roche, Indianapolis, MN, USA) according to the manufacturer's protocol. Peripheral lymphocytes from each patient were used as the source of normal DNA.

Microsatellite analysis. Twelve fluorescently labeled primer pairs were used for microsatellite analysis: MBP, D9S162, IFNA, D16S476, D16S310, D18S51, D4S243, FGA, ACTBP, D9S171, D9S747, and MJD. Primer sequences were retrieved from the human genome database (http://www.gdb. org). PCR reactions were performed with $1 \mathrm{U}$ of AmpliTaq Gold polymerase on $2 \mu \mathrm{l}$ extracted DNA in a final volume of $25 \mu 1$ as follows: one denaturation step at $95^{\circ} \mathrm{C}$ for $10 \mathrm{~min}, 35$ cycles of denaturation at $95^{\circ} \mathrm{C}$ for $1 \mathrm{~min}$, and annealing and extension at $60^{\circ} \mathrm{C}$ for $1 \mathrm{~min}$. The $60^{\circ} \mathrm{C}$ annealing temperature is optimal for all primers (optimization data not shown). The PCR products were analyzed on a fluorescent DNA sequencer (ABI 310 genetic analyzer, Applied Biosystems, USA).

Urinary and tumor DNA were considered to show a deletion if an allele was reduced by $>50 \%$.

Optimization. In order to assess the standard deviation (SD) of the peak height ratios we performed parallel isolations $(3 \mathrm{x}), \mathrm{PCR}$ reactions $(3 \mathrm{x})$ and electrophoresis $(3 \mathrm{x})$. While we optimized the method we observed that when the relative fluorescence (RFU) did not reach 100, the SD of the peak height ratios increased, rendering these data unreliable. These cases were marked as 'amplification failure' and were excluded from the data evaluation.

Statistical analysis. The Cochran-Armitage trend test was performed to calculate which marker showed correlation with the pathological data.

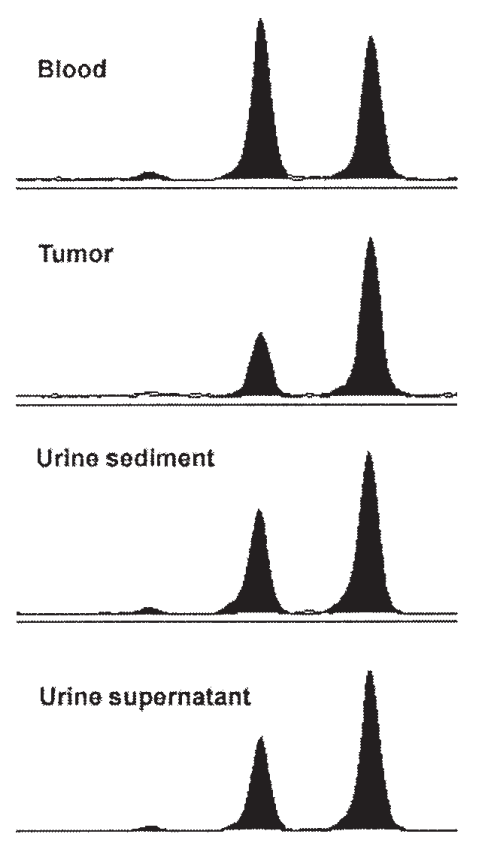

Figure 1. LOHs on the $9 \mathrm{q} 32$ region.

\section{Results}

Microsatellite analysis was performed on blood, tumor and urine samples of 40 patients suffering from bladder cancer using 12 microsatellite markers. The average SD of the peak height ratios among parallel isolations of the 12 markers was very low $(0.030,+0.084$, and -0.008$)$.

Twenty-two out of the 26 tumor specimens showed at least one $\mathrm{LOH}(85 \%)$. Detecting $\mathrm{LOH}$ in urine has a practical advantage since its sensitivity is of importance. At least one genetic alteration was found in the urine supernatant or sediment in 38 out of 44 urine samples (86\%). The sensitivity of the supernatant alone was $80 \%(35 / 44)$, whereas that of the sediment was $68 \%(27 / 40)$ (Tables I and II).

The urine supernatant of the superficial (Ta/T1) tumors had a sensitivity of $84 \%(21 / 25)$, while that of the sediment was $67 \%(14 / 21)$. Urine samples taken from patients with muscle-invading tumors (T2/T3) had similar sensitivities; $74 \%(14 / 19)$ in the supernatant and 68\% (13/19) in the sediment.

Regarding the 20 control patients with non-malignant urologic disease we detected LOHs in 4 patients (6 LOHs) (Tables I and II). One of them had urinary incontinence (LOH for 4 markers), another had cystitis ( $\mathrm{LOH}$ for 1 marker) and 2 had BPH. Based on these data, the specificity of the method among patients with urological symptoms was evaluated as $80 \%(16 / 20)$.

Among the healthy controls we also found LOHs ( 2 in the urine sediment and 3 in the urine supernatant) in the urine samples of four individuals (Tables I and II). Therefore, the specificity of microsatellite analysis in this group was $(13 / 16) 81 \%$ for the urine supernatant and $87.5 \%$ (14/16) for the urine sediment.

LOH was detected most frequently at the 9p21 (46\%), $9 \mathrm{q} 32(34 \%)$ and $5 \mathrm{q} 15(34 \%)$ regions. The sensitivity reached $57 \%$ if 2 markers $(9 \mathrm{p} 21,4 \mathrm{q} 32)$ and $64 \%$ if 3 markers $(9 \mathrm{p} 21$, $4 \mathrm{q} 32$ and $16 \mathrm{q} 24)$ were used. 
Table I. Summary of the raw data after microsatellite analysis. ${ }^{a}$

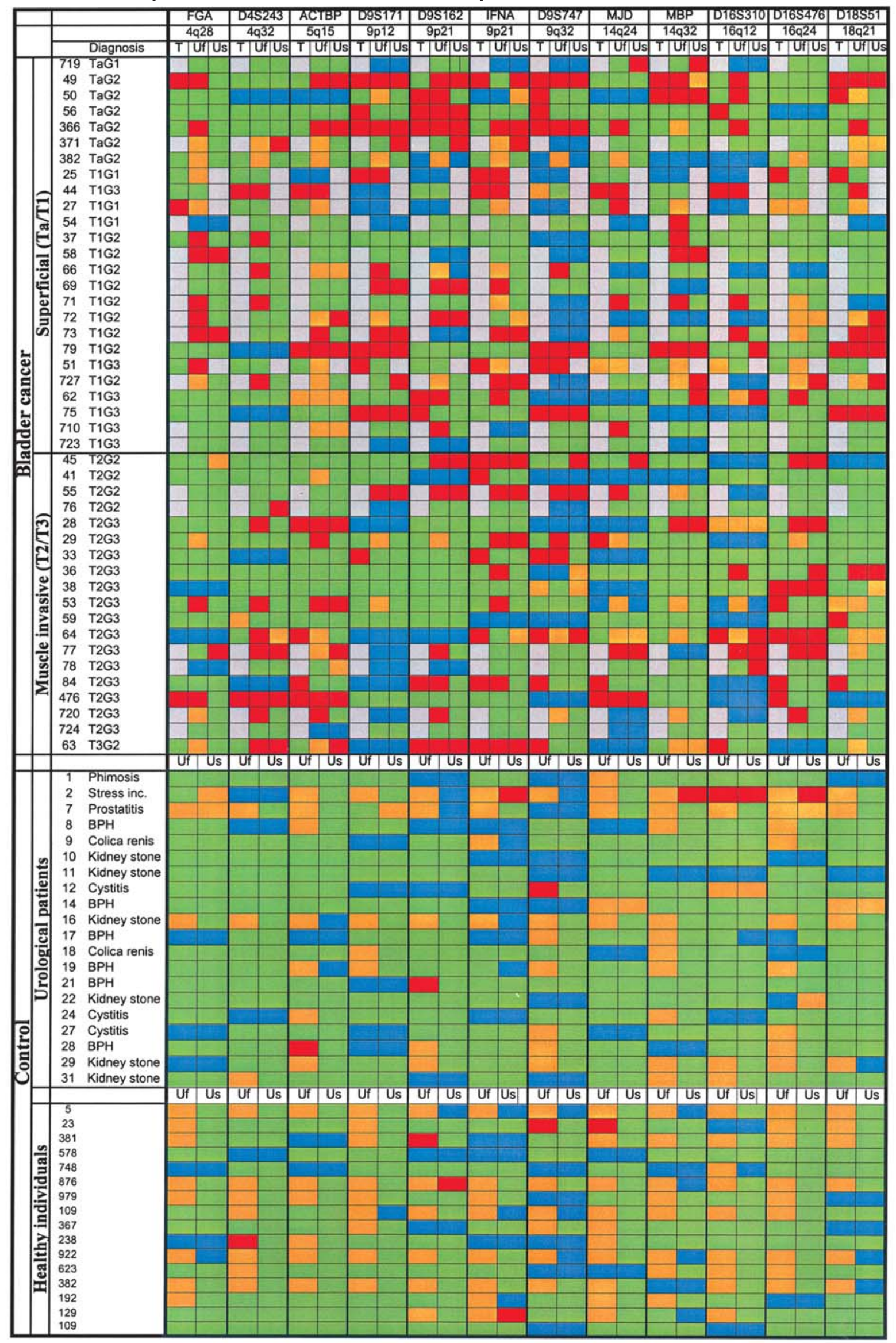

${ }^{a}$ Microsatellite analysis of tumor (T), urine sediment (Us), and urine supernatant (Uf). LOHs are shown in red boxes. Blue boxes indicate the homozygous (not informative) cases, the gray boxes indicate missing samples and the yellow boxes represent 'amplification failures'. Stage and grade are shown in the first column. The analyzed chromosomal regions are in the first row. 
Table II. Specificity and sensitivity of the microsatellite analysis.

\begin{tabular}{|c|c|c|c|c|c|}
\hline \multirow[b]{3}{*}{$\begin{array}{l}\mathrm{LOH} \text { in at least } \\
\text { one sample }\end{array}$} & \multicolumn{3}{|c|}{ Bladder cancer patients } & \multirow{2}{*}{$\begin{array}{c}\begin{array}{c}\text { Control } \\
\text { patients }\end{array} \\
(n=20)\end{array}$} & \multirow{2}{*}{$\begin{array}{l}\begin{array}{l}\text { Healthy control } \\
\text { patients }\end{array} \\
\quad(n=16)\end{array}$} \\
\hline & $\begin{array}{l}\text { Superficial } \\
\qquad(\mathrm{n}=25)\end{array}$ & $\begin{array}{l}\text { Muscle invasive } \\
\qquad(\mathrm{n}=19)\end{array}$ & $\sum_{(n=44)}^{\sum}$ & & \\
\hline & $23 / 25 \quad 92 \%$ & $18 / 19 \quad 95 \%$ & $41 / 44 \quad 93 \%$ & $4 / 20 \quad 20 \%$ & $5 / 16 \quad 31 \%$ \\
\hline $\begin{array}{l}\text { A minimum of one } \mathrm{LOH} \\
\text { in the urine supernatant }\end{array}$ & $21 / 25 \quad 84 \%$ & $14 / 19 \quad 74 \%$ & $35 / 44 \quad 80 \%$ & $4 / 20 \quad 20 \%$ & $3 / 16 \quad 19 \%$ \\
\hline $\begin{array}{l}\text { A minimum of one } \mathrm{LOH} \\
\text { in the urine sediment }\end{array}$ & $14 / 21 \quad 67 \%$ & $13 / 19 \quad 68 \%$ & $27 / 40 \quad 68 \%$ & $1 / 20 \quad 5 \%$ & $2 / 16 \quad 12.5 \%$ \\
\hline
\end{tabular}

\section{Discussion}

The accumulation of genetic alterations including deletions is one of the main features of tumors. In accordance with other groups, we concluded that the assessment of genetic loss by microsatellite analysis offers a sensitive tool for detecting bladder cancer $(11,20)$. The successful detection of genetic errors in the urine bears great importance in the diagnosis and follow-up of patients with bladder carcinoma (21).

The contamination with normal DNA is a major concern of microsatellite analysis. In the presence of contaminating normal DNA, both alleles, even the one deleted in the tumor, become amplified during PCR. As this can mask the LOH present in tumor cells, it reduces the sensitivity of detection. The proportion of DNA originating from normal cells versus tumor cells in the urine sediment cannot be assessed in advance; it is likely to depend on the tumor size and/or the amount of inflammatory cells in the urine. On the other hand, increased amounts of cell-free DNA were observed in the plasma/serum of cancer patients (15-19). These amounts are proportional to tumor burden, and in at least some cancer patients nearly the whole free DNA content of the plasma is derived from tumor cells $(22,23)$. Elevated cell-free DNA levels were found, not only in the plasma, but also in other body fluids such as pleural fluid and urine, in cancer patients $(17,24)$. Zancan and colleagues were able to detect bladder cancer in all of the cases when the urinary cell-free DNA concentration was $>250 \mathrm{ng} / \mathrm{ml}$ (17). However, the origin of this DNA fraction has not been fully clarified. Jahr and coworkers demonstrated the apoptotic and necrotic origin of free DNA in the serum and concluded that it principally was derived from the expanding tumor tissue (25).

Our objective was to examine whether the sensitivity of microsatellite analysis could be improved by separating urine sediment from the supernatant, assuming that the free DNA in the supernatant originates mainly from the disintegrated cells of the tumor.

The overall sensitivity of the method in urine samples (supernatants and sediments) was $86 \%$. The detection rate was the highest in the superficial ( $\mathrm{Ta} / \mathrm{T} 1)$ cases $(23 / 25,92 \%)$, while it was lower in the muscle invasive (T2/T3) ones $(15 / 19,79 \%)$ (Tables I and II). Sensitivity was $68 \%$ in the urine sediment, and $80 \%$ in the supernatant. These results confirm that the use of the urine supernatant enhances the sensitivity of microsatellite analysis.

Sixty-seven percent of the genetic alterations found in the tumors were identified in the corresponding urine supernatant. Notably, we also detected alterations that were not present in the examined tumor specimen. These alterations may have originated from other tumor clone(s) also present in the tumor but not in the examined specimen.

In the literature, specificity is almost exclusively determined by using samples from healthy people, thus a sensitivity of $100 \%$ is reported (26-29). On the other hand, it might be interesting to observe how other urologic diseases affect sensitivity. Two studies dealing with this problem have provided conflicting results. In one study of BPH and cystitis it was found that inflammation can also cause genetic alterations, thus deteriorating the sensitivity of tumor detection (19). In the other study, no loss of heterozygosity was found in the control group including five patients with cystitis (20).

Out of 20 control patients with other urological problems, 4 exhibited loss of heterozygosity (Table II). One of these patients was treated for urinary stress incontinence, another with cystitis, whereas in the other two individuals BPH was diagnosed. Based on these data, the specificity of the method in this group in respect to urine supernatant and urine sediment was evaluated as $80 \%$. However, these data have to be considered critically since we were unable to track the control patients having $4 \mathrm{LOHs}$ in the urine sample. Therefore we could not exclude the presence of bladder cancer.

We found LOHs in 3 out of the 16 healthy control patient samples; 2 in the urine sediment and 3 in the urine supernatant (Tables I and II). Hence, the evaluated specificity in this group was $81 \%$ in the case of the urine supernatant and $87.5 \%$ in the case of the urine sediment. However, the low DNA content (1) of the urine supernatant was a general attribute of these specimens. This can influence the amplification by either causing 'amplification failure' or alteration of allelic ratio. We performed parallel reproducibility experiments and found that the SDs of the peak height ratios increase strongly if the relative fluorescence (RFU) 
fails to reach 100 . In order to avoid this problem we excluded these unreliable results $(\mathrm{RFU}<100)$ from the analysis.

Notably the distribution of poor amplifications $(\mathrm{RFU}<100)$ from the urine supernatant was variable among the three groups. In the tumor patients the failure rate was $15 \%$, in the urological control group it was $27 \%$, and in the healthy individuals it was $48 \%$, in contrast with the urine sediment where similar failure rates were found in all three groups (4, 3 , and $0 \%$ ). This further supports the formerly cited theory that the DNA content of urine supernatant, but not of the sediment, is elevated in the presence of a tumor.

The most effective marker was the IFNA in the 9p21 chromosomal region which showed LOH in $46 \%$ of the cases and $57 \%$ if combined with D4S243 (4q32). The use of D16S476 (16q24) as a third marker increased the sensitivity to $64 \%$.

The loss of the chromosomal region $16 q 24$ showed a strong correlation with tumor stage $(\mathrm{p}=0.02)$ but not with grade $(\mathrm{p}=0.11)$. This marker may have a prognostic value.

\section{Acknowledgements}

We are grateful for the financial assistance of the National Research and Development Program (project no. NKFP1a/0023/2002) and the National Office for Research and Technology (project no. OMFB-606/2003).

\section{References}

1. Fearon ER and Vogelstein B: A genetic model for colorectal tumorigenesis. Cell 61: 759-767, 1990.

2. Lengauer C, Kinzler KW and Vogelstein B: Genetic instabilities in human cancers. Nature 396: 643-649, 1998.

3. Mao L, Lee DJ, Tockman MS, Erozan YS, Askin F and Sidransky D: Microsatellite alterations as clonal markers for the detection of human cancer. Proc Natl Acad Sci USA 91: 9871-9875, 1994.

4. Cavenee WK, Dryja TP, Phillips RA, Benedict WF, Godbout R, Gallie BL, Murphree AL and Strong LC: Expression of recessive alleles by chromosomal mechanisms in retinoblastoma. Nature 305: 779-784, 1983.

5. Cohen SM and Johansson SL: Epidemiology and etiology of bladder cancer. Urol Clin N Am 19: 421-428, 1992.

6. Heney NM, Ahmed S, Flanagan MJ, Frable W, Corder MP, Hafermann MD and Hawkins IR: Superficial bladder cancer: progression and recurrence. J Urol 130: 1083-1086, 1983.

7. Farrow GM, Utz DC and Rife CC: Morphological and clinical observations of patients with early bladder cancer treated with total cystectomy. Cancer Res 36: 2495-2501, 1976.

8. Lewis RW, Jackson AC, Murphy WM, Leblanc GA and Meehan WL: Cytology in the diagnosis and follow-up of transitional cell carcinoma of the urothelium: Review with a case series. J Urol 116: 43-46, 1976.

9. Saran KK, Gould D, Godec CJ and Verma RS: Genetics of bladder cancer. J Mol Med 74: 441-445, 1996.

10. Orntoft TF and Wolf H: Molecular alterations in bladder cancer. Urol Res 26: 223-233, 1998.

11. Mao L, Schoenberg M, Scicchitano M, Erozan YS, Merlo A, Schwab D and Sidransky D: Molecular detection of primary bladder cancer by microsatellite analysis. Science 271: 659-662, 1996.
12. Bartoletti R, Dal Canto M, Cai T, Piazzini M, Travaglini F, Gavazzi A and Rizzo M: Early diagnosis and monitoring of superficial transitional cell carcinoma by microsatellite analysis on urine sediment. Oncol Rep 13: 531-537, 2005.

13. Keen AJ and Knowles MA: Definition of two regions of deletion on chromosome 9 in carcinoma of the bladder. Oncogene 9: 2083-2088, 1994.

14. Utting M, Werner W, Dahse R, Schubert J and Junker K Microsatellite analysis of free tumor DNA in urine, serum and plasma of patients: a minimally invasive method for the detection of bladder cancer. Clin Cancer Res 8: 35-40, 2002.

15. Shapiro B, Chakrabarty $M$, Chon EM and Leon SA: Determination of circulating DNA levels in patients with benign or malignant tumors. Cancer 51: 2116-2120, 1983.

16. Schmidt B, Engel E, Carstensen T, Weickmann S, John M, Witt $\mathrm{C}$ and Fleischhacker M: Quantification of free RNA in serum and bronchial lavage: a new diagnostic tool in lung cancer detection? Lung Cancer 48: 145-147, 2005. E-pub Dec 16,2004

17. Zancan M, Franceschini R, Mimmo C, Vianello M, Di Tonno F, Mazzariol C, Malossini G and Gion M: Free DNA in urine: a new marker for bladder cancer? Preliminary data. Int J Biol Markers 20: 134-136, 2005.

18. Taback B and Hoon DS: Circulating nucleic acids in plasma and serum: past, present and future (Review). Curr Opin Mol Ther 6: 273-278, 2004

19. Anker P, Mulcahy H, Chen XQ and Stroun M: Detection of circulating tumor DNA in the blood (plasma/serum) of cancer patients. Cancer Metastasis Rev 18: 65-73, 1999.

20. Mourah S, Cussenot O, Vimont V, Desgrandchamps F, Teillac P, Cochant-Priollet B, Le Duc A, Fiet J and Soliman H: Assessment of microsatellite instability in urine in the detection of transitional-cell carcinoma of the bladder. Int J Cancer 79: 629-633, 1998.

21. Amira N, Mourah S, Rozet F, Teillac P, Fiet J, Aubin P, Cortesse A, Desgrandchamps F, Le Duc A, Cussenot O and Soliman H: Non-invasive molecular detection of bladder cancer recurrence. Int J Cancer 101: 293-297, 2002.

22. Goessl C, Heicappell R, Munker R, Anker P, Stroun M, Krause H, Muller M and Miller K: Microsatellite analysis of plasma DNA from patients with clear cell renal carcinoma. Cancer Res 58: 4728-4732, 1998 .

23. Nawroz H, Koch W, Anker P, Stroun M and Sidransky D: Microsatellite alterations in serum DNA of head and neck cancer patients. Nat Med 2: 1035-1037, 1996.

24. Chan MH, Chow KM, Chan AT, Leung CB, Chan LY, Chow KC, Lam CW and Lo YM: Quantitative analysis of pleural fluid cellfree DNA as a tool for the classification of pleural effusions. Clin Chem 49: 740-745, 2003.

25. Jahr S, Hentze H, Englisch S, Hardt D, Fackelmayer FO, Hesch RD and Knippers R: DNA fragments in the blood plasma of cancer patients: quantitations and evidence for their origin from apoptotic and necrotic cells. Cancer Res 61: 1659-1665, 2001 .

26. Eissa S, Kassim S and El-Ahmady O: Detection of bladder tumors: role of cytology, morphology-based assays, biochemical and molecular markers. Curr Opin Obstet Gynecol 15: 395-403, 2003.

27. von Knobloch R, Hegele A, Brandt H, Olbert P, Heidenreich A and Hofmann R: Serum DNA and urine DNA alterations of urinary transitional cell bladder carcinoma detected by fluorescent microsatellite analysis. Int J Cancer 94: 67-72, 2001.

28. Christensen M, Wolf $\mathrm{H}$ and Orntoft TF: Microsatellite alterations in urinary sediments from patients with cystitis and bladder cancer. Int J Cancer 85: 614-617, 2000.

29. Little B, Hughes A, Young MR and O'Brien A: Use of polymerase chain reaction analysis of urinary DNA to detect bladder carcinoma. Urol Oncol 23: 102-107, 2005. 